\title{
Taxonomic Relationships of an Endangered Japanese Salamander Hynobius hidamontanus Matsui, 1987 with $H$. tenuis Nambu, 1991 (Amphibia: Caudata)
}

\author{
MASAFUMI MATSUI $^{1 *}$, KANTO NISHIKAWA ${ }^{1}$, YASUCHIKA MISAWA ${ }^{2}$, \\ MASAICHI KAKEGAWA ${ }^{3}$, AND TAKAHIRO SUGAHARA ${ }^{4}$ \\ ${ }^{1}$ Graduate School of Human and Environmental Studies, Kyoto University, Yoshida- \\ Nihonmatsu-cho, Sakyo-ku, Kyoto 606-8501, JAPAN \\ ${ }^{2}$ Civil Engineering and Eco-Technology Consultants, Higashi-ikebukuro 2-23-2, \\ Toshima-ku, Tokyo 170-0013, JAPAN \\ ${ }^{3}$ Matsugaya 3-2-8, Taito-ku, Tokyo 111-0036, JAPAN \\ ${ }^{4}$ Hazama-cho 1740-1, Hachioji, Tokyo 193-0941, JAPAN
}

\begin{abstract}
We assessed the taxonomic relationships of an endangered Japanese small salamander, Hynobius hidamontanus Matsui, 1987, and its close relative $H$. tenuis Nambu, 1991 electrophoretically and found that they were not clearly distinguished from each other. This result, together with available morphological and ecological information, strongly indicates that $H$. tenuis Nambu, 1991 is a subjective junior synonym of $\boldsymbol{H}$. hidamontanus Matsui, 1987. By this conclusion, the total distribution range of $\boldsymbol{H}$. hidamontanus is greatly expanded, but its endangered status and the necessity of its conservation is not be changed since the habitats of this species are fragmented and not continuous. The distribution pattern of this species is interesting from the viewpoint of biogeography.
\end{abstract}

Key words: Hynobiidae; Allozyme; Specific status; Conservation; Biogeography; Japan

\section{INTRODUCTION}

Reliable taxonomic identification of animals forms a fundamental basis for estimating species richness, which forms the most important basis in conserving animal biodiversity (May, 1995). Through the use of biochemical techniques, the presence of many new species has been elucidated in various animals, and this has rapidly increased the known species diversity of animals including amphibians (e.g.,

* Corresponding author. Tel/Fax: + 81-75-7536846; E-mail address: fumi@zoo.zool.kyoto-u.ac.jp
Glaw et al., 1998).

Pertinent taxonomic identification of populations of a species also affects appropriate measures of conservational and protective status of each species. Currently, species formerly considered to be widespread in their distribution and omitted from "Red List" tend to be split into several distinct species, and each of these needs new conservation measures because of its more restricted range of distribution (e.g., Nishikawa et al., 2001).

However, though the number of cases is fewer, more than one species hitherto considered to be distinct from others has been 
proven to be identical to another species through extensive biochemical studies. We herewith report such a case found in two species of Japanese hynobiid salamanders.

Matsui (1987) described a salamander, $H$. hidamontanus, from a montane region of Nagano Prefecture, central Honshu, mainland of Japan, on the basis of morphological and biochemical evidence. The species was later listed as an endangered species in IUCN (IUCN, 1996) and Japanese (Matsui, 2000a) Red Data Books. On the other hand, Nambu (1983) reported the occurrence of hynobiid salamanders from montane regions of Toyama and Niigata Prefectures, surrounding Nagano. Although Matsui (1987: 62) pointed out that these salamanders share diagnostic characteristics with $H$. hidamontanus, Nambu (1991) described them as a separate species, $H$. tenuis, on the basis of a specimen from Arimine, Ooyama-machi, Toyama Prefecture. Nambu (1991), while also considering this species to be closely related to $H$. hidamontanus Matsui, 1987 in sharing several morphological characteristics, such as the lack of the fifth toe, the small number of vomerine teeth, and similar body proportions, argued for its difference from the latter in skull morphology (Nambu, 1991: 995).

Nambu (1991), however, did not make any quantitative analyses such as statistical comparisons of morphological characteristics using a large number of specimens or electrophoretic assessment of genetic differentiation, both of which are routine in the taxonomic study of hynobiid salamanders (e.g., Matsui and Miyazaki, 1984; Matsui, 1987; Matsui et al., 1992).

The taxonomic validity of $H$. tenuis, therefore, remains dubious (Matsui, 1996b, 2000a), but no study has been conducted to reassess the taxonomic relationship of this species and $H$. hidamontanus. Because, as noted above, $H$. hidamontanus is now considered to be endangered (IUCN, 1996; Matsui, 2000a), elucidation of the taxonomic relationships of $H$. tenuis and $H$. hidamontanus has become urgent from the viewpoint of species conservation.

Small salamanders of the genus Hynobius exhibit high inter- and intraspecific variations in morphology, and, therefore, species identification is usually difficult without locality information (Matsui and Miyazaki, 1984). For studies of intra- and interspecific variations and taxonomy among morphologically similar urodelan species, electrophoretic studies contribute the best data (e.g., Matsui et al., 1992, 2000; Jackman and Wake, 1994; Highton, 1999). Indeed, recent genetic analyses by electrophoresis have elucidated many taxonomic problems in Hynobius (e.g., Matsui 1987; Nishikawa et al., 2001). Herein, we examined the taxonomic validity of $\boldsymbol{H}$. tenuis chiefly by means of this technique.

\section{MATERIALS AND METHODS}

The small Japanese salamanders generally occur allopatrically (Matsui, 1996a), and only one species has been recorded from each of the type localities of $H$. hidamontanus and $H$. tenuis (Matsui, 1996b). Therefore, there is little possibility that samples collected from each of these localities will include more than one species. In addition to this, $H$. hidamontanus closely resembles $H$. lichenatus in external morphology (Matsui and Matsui, 1980), but is reported to form a genetic group not with the latter but with $H$. nebulosus (Matsui, 1987). We therefore used both $H$. lichenatus and $H$. nebulosus for comparisons. Further, because populations of many small Japanese salamanders are in decline (Matsui, 2000a), we need to refrain from collecting a large number of specimens. Bearing this in mind, we used a total of 46 specimens to evaluate genetic relationships among four species: $H$. tenuis from Toyama (sample 1, topotypic population, $\mathrm{N}=13$ ), and Gifu (sample 2, N=7) Prefectures, $H$. hidamontanus from Nagano Prefecture (sample 3 , topotypic population, $\mathrm{N}=16$ ), and one population each of $H$. nebulosus from Shiga Prefecture (sample 4, N=4) and H. lichenatus 


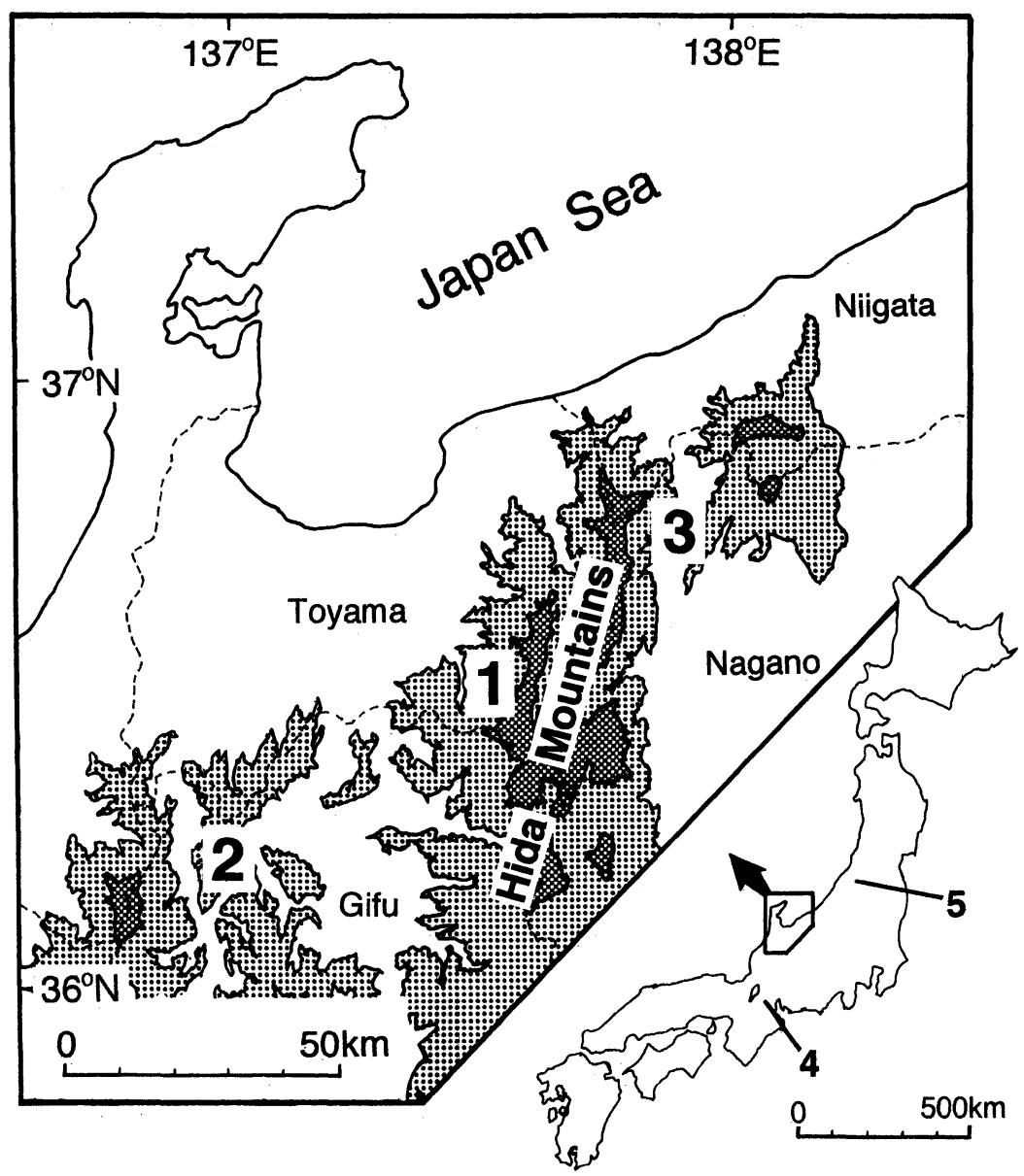

FIG. 1. A map of northern Central Honshu, Japan, showing sampled localities of hynobiid species used in this study. For sample numbers, refer to text. Coarsely dotted area $>1000 \mathrm{~m}$ asl. Finely dotted area $>2000 \mathrm{~m}$ asl.

from Yamagata Prefecture (sample 5, $\mathrm{N}=6$ ) (Fig. 1).

In the laboratory, liver samples were removed from fully anesthetized salamanders and stored at $-84 \mathrm{C}$. Voucher specimens were fixed in $10 \%$ formalin, preserved in $70 \%$ ethanol, and deposited in the Graduate School of Human and Environmental Studies, Kyoto University (KUHE) (see Appendix). Supernate fraction and homogenates were examined by standard horizontal starch gel electrophoresis (Shaw and Prasad, 1970; Ayala et al., 1972), containing Starch Art (Starch Art Corp., Smithville, USA) and Connaught starch (Connaught Lab., Ontario, Canada) mixed in a 4:1 ratio and then suspended in buffer at a concentration of $11.5 \%$. Enzymes examined, locus designations, and buffer systems employed are listed in Table 1. Staining methods, genetic interpretations of allozyme data, enzyme nomenclature, E. C. numbers, abbreviations, and isozyme designations follow Nishikawa et al. (2001).

We studied 19 enzyme systems coded by 24 presumptive loci (Table 1). Genetic variability for each sample was assessed by the standard analyses: percentage loci polymorphic ( $\mathrm{P}$, a locus is considered as polymorphic unless the frequency of the most common allele exceeds 0.95 ), the mean heterozygosity 
TABLE 1. Enzymes, presumptive loci, and buffer systems used in the analyses of allozyme variations among Hynobius species.

\begin{tabular}{llll}
\hline \multicolumn{1}{c}{ Enzymes } & E.C. numbers & \multicolumn{1}{c}{ Locus } & Buffer system* \\
\hline Aconitate hydratase & 4.2 .1 .3 & mAcoh-A & TC8 \\
Aspartate aminotransferase & 2.6 .1 .1 & mAat-A & CAPM6 \\
Aspartate aminotransferase & 2.6 .1 .1 & sAat-A & CAPM6, TC7 \\
Alcohol dehydrogenase & 1.1 .1 .1 & Adh-A & TBE8.7 \\
Fumarate hydratase & 4.2 .1 .1 & Fumh-A & TBE8.7 \\
Glucose-6-phosphate isomerase & 5.3 .1 .9 & Gpi-A & CAPM6 \\
Glycerol-3-phosphate dehydrogenase & 1.1 .1 .8 & G3pdh-A & TC8 \\
Glutamate dehydrogenase & 1.4 .1 .3 & Gtdh-A & TC8 \\
Guanine deamidase & 3.5 .4 .3 & Gda-A & TBE8.7 \\
3-Hydroxybuthyrate dehydrogenase & 1.1 .1 .30 & Hbdh-A & CAPM6 \\
Isocitrate dehydrogenase & 1.1 .1 .42 & mIdh-A & TC7 \\
L-Lactate dehydrogenase & 1.1 .1 .27 & Ldh-A & CAPM6, TC7 \\
L-Lactate dehydrogenase & 1.1 .1 .27 & Ldh-B & CAPM6, TC7 \\
Malate dehydrogenase & 1.1 .1 .37 & mMdh-A & CAPM6, TC8 \\
Malate dehydrogenase & 1.1 .1 .37 & sMdh-A & CAPM6, TC8 \\
Malic enzyme** & 1.1 .1 .40 & mMdhp-A & TC7 \\
Malic enzyme** & 1.1 .1 .40 & sMdhp-A & TC7 \\
Peptidase (leucyl-glycine) & $3.4 .11 .-$ & Pep-A & TBE8.7 \\
Phosphoglucomutase & 5.4 .2 .2 & Pgm-A & TC7 \\
Phosphoglucomutase & 5.4 .2 .2 & Pgm-C & TC7 \\
Phosphogluconate dehydrogenase & 1.1 .1 .44 & Pgdh-A & TC7 \\
Sorbitol dehydrogenase & 1.1 .1 .14 & Sdh-A & CAPM6 \\
Superoxide dismutase & 1.15 .1 .1 & Sod-A & TBE8.7 \\
Xanthine dehydrogenase & 1.1 .1 .204 & Xdh-A & TC8 \\
\hline
\end{tabular}

* Buffer systems-CAPM6: Citrate-aminopropylmorpholine, $\mathrm{pH}=6.0$ (Clayton and Tretiak, 1972), TC7: Triscitrate, $\mathrm{pH}=7.0$ (Shaw and Prasad, 1970), TC8: Tris-citrate, $\mathrm{pH}=8.0$ (Clayton and Tretiak, 1972), TBE8.7: Tris-borate-EDTA, $\mathrm{pH}=8.7$ (Boyer et al., 1963).

** NADP-dependent malate dehydrogenase.

by direct count $(\mathrm{H})$, and the mean number of electromorphs per locus (A).

In order to estimate overall genetic divergence among samples, we calculated two genetic distances: Nei's (1978) unbiased genetic distance and modified Rogers' distance (Wright, 1978). We inferred patterns of phenetic similarities among samples from Nei's (1978) distance clustered by the UPGMA algorithm (Sneath and Sokal, 1973), and modified Rogers' distance clustered by the Neighborjoining (NJ) procedure (Saitou and Nei, 1987). Hynobius lichenatus (sample 5) was designated as an outgroup in the NJ method.

We ran these analyses by employing BIOSYS-1 (Swofford and Selander, 1981) and PHYLIP vers. 3.5 C computer programs (Felsenstein, 1993).

\section{RESULTS}

Fifty-two alleles were detected at 24 putative loci of which 16 (other than mAat-A, mAcoh-A, Fumh-A, Gtdh-A, sMdhp-A, PgmA, Sdh-A, and Sod-A) were variable (Table 2). The most variable loci were Gda-A, 
Gpi-A, and Pgdh-A, each with four alleles, followed by Adh-A, G3pdh-A, mIdh-A, Ldh$\mathrm{B}$, sMdh-A, and Xdh-A, each with three alleles. Adh-A in $H$. nebulosus, and sAat-A, Adh-A, Hbdh-A, and sMdh-A in H. lichenatus were fixed by unique alleles that were not shared with other species. We found no unique alleles in either $H$. tenuis or $H$. hidamontanus.
However, we found some differentiations of allelic frequencies in Gda-A, Gpi-A, and LdhA, among $H$. tenuis and $H$. hidamontanus (samples 1-3).

The mean number of electromorphs per locus (A) varied from 1.1 to 1.3 , the percentage of polymorphic loci (P) from 4.2 to 25.0 , and the mean heterozygosity $(\mathrm{H})$ from

TABLE 2. Allele frequencies at 16 polymorphic loci of Hynobius samples examined. For sample numbers, refer to Fig. 1 and text. $A=$ mean number of alleles per locus; $\mathrm{P}=$ percentage of loci; $\mathrm{H}=$ mean heterozygosity by direct count.

\begin{tabular}{|c|c|c|c|c|c|}
\hline \multirow[b]{3}{*}{ Locus } & \multicolumn{5}{|c|}{ Species and sample number $(\mathrm{N})$} \\
\hline & tenuis & tenuis & hidamontanus & nebulosus & lichenatus \\
\hline & $1(13)$ & $2(7)$ & $3(16)$ & $4(4)$ & $5(6)$ \\
\hline sAat-A & a1.000 & a1.000 & a1.000 & a1.000 & b1.000 \\
\hline Adh-A & a1.000 & a1.000 & a1.000 & $\mathrm{c} 1.000$ & b1.000 \\
\hline \multirow[t]{3}{*}{ Gda-A } & $\mathrm{a} 0.923$ & $\mathrm{a} 0.143$ & a1.000 & b1.000 & b1.000 \\
\hline & $\mathrm{d} 0.077$ & c0.429 & & & \\
\hline & & d0.429 & & & \\
\hline \multirow[t]{2}{*}{ G3pdh-A } & b1.000 & b1.000 & $\mathrm{a} 0.063$ & $\mathrm{c} 1.000$ & c1.000 \\
\hline & & & b0.938 & & \\
\hline \multirow[t]{3}{*}{ Gpi-A } & $\mathrm{b} 0.462$ & b1.000 & b1.000 & $\mathrm{a} 0.375$ & b0.833 \\
\hline & $\mathrm{c} 0.192$ & & & $\mathrm{c} 0.500$ & d0.167 \\
\hline & $\mathrm{d} 0.346$ & & & d0.125 & \\
\hline Hbdh-A & a1.000 & a1.000 & a1.000 & a1.000 & b1.000 \\
\hline \multirow[t]{2}{*}{ mIdh-A } & $\mathrm{a} 0.962$ & a1.000 & a1.000 & $\mathrm{a} 0.500$ & $\mathrm{a} 0.833$ \\
\hline & b0.038 & & & $\mathrm{c} 0.500$ & b0.167 \\
\hline \multirow[t]{2}{*}{ Ldh-A } & $\mathrm{a} 0.077$ & a1.000 & b1.000 & a1.000 & b1.000 \\
\hline & b0.923 & & & & \\
\hline \multirow[t]{2}{*}{ Ldh-B } & $\mathrm{c} 1.000$ & $\mathrm{c} 1.000$ & c1.000 & a0.500 & c1.000 \\
\hline & & & & b0.500 & \\
\hline \multirow[t]{2}{*}{ mMdh-A } & b1.000 & b1.000 & b1.000 & b1.000 & a0.167 \\
\hline & & & & & $\mathrm{b} 0.833$ \\
\hline \multirow[t]{2}{*}{ sMdh-A } & $\mathrm{c} 1.000$ & $\mathrm{c} 1.000$ & c1.000 & a0.250 & b1.000 \\
\hline & & & & $\mathrm{c} 0.750$ & \\
\hline \multirow[t]{2}{*}{ mMdhp-A } & b1.000 & b1.000 & b1.000 & b1.000 & a0.167 \\
\hline & & & & & b0.833 \\
\hline Pep-A & b1.000 & b1.000 & b1.000 & a1.000 & a1.000 \\
\hline \multirow[t]{4}{*}{ Pgdh-A } & $\mathrm{c} 1.000$ & $\mathrm{c} 1.000$ & $\mathrm{c} 1.000$ & a1.000 & $\mathrm{a} 0.083$ \\
\hline & & & & & b0.083 \\
\hline & & & & & c0.083 \\
\hline & & & & & d0.750 \\
\hline \multirow[t]{2}{*}{ Pgm-C } & a1.000 & a1.000 & a0.938 & a0.125 & a1.000 \\
\hline & & & b0.063 & b0.875 & \\
\hline \multirow[t]{2}{*}{ Xdh-A } & $\mathrm{a} 0.923$ & a1.000 & a0.969 & $\mathrm{a} 0.750$ & a1.000 \\
\hline & $\mathrm{c} 0.077$ & & b0.031 & $\mathrm{c} 0.250$ & \\
\hline A & 1.3 & 1.1 & 1.1 & 1.3 & 1.3 \\
\hline $\mathrm{P}$ & 16.4 & 4.2 & 8.3 & 25.0 & 20.8 \\
\hline $\mathrm{H}$ & 0.010 & 0.000 & 0.003 & 0.031 & 0.021 \\
\hline
\end{tabular}


0.00 to 0.03 (Table 2). The highest $\mathrm{A}, \mathrm{P}$, and $\mathrm{H}$ values were found in $H$. nebulosus (sample 4), while the lowest A value was seen in $H$. tenuis from Gifu Prefecture (sample 2 ) and $H$. hidamontanus (sample 3 ), and the lowest $\mathrm{P}$ and $\mathrm{H}$ values were shown by $H$. tenuis from Gifu Prefecture (sample 2).

As shown in Table 3, the highest Nei's (1978) and modified Rogers' distances were obtained between $H$. tenuis (sample 2) and $H$. lichenatus (sample 5) (0.46 and 0.60 , respectively). By contrast, the lowest distances were found between $H$. tenuis from Toyama Prefecture (sample 1) and $H$. hidamontanus (sample 3) (0.01 and 0.10, respectively).

Results of UPGMA and NJ analyses are shown in Fig. 2. In both phenograms, $H$. tenuis from Toyama Prefecture (sample 1) joined with $H$. hidamontanus (sample 3) first, and then with $H$. tenuis from Gifu Prefecture (sample 2): the two populations of $H$. tenuis were not clustered as one group. In the UPGMA tree, relationships among the three groups, the tenuis-hidamontanus group, $H$. nebulosus (sample 4), and $H$. lichenatus (sample 5) were not solved clearly, but distances among them were substantially large.

TABLE 3. Matrix of Nei's (1978) unbiased genetic distance (above diagonal) and modified Rogers' distance (Wright, 1978: below diagonal). Diagonal numbers show the numbers of loci fixed by unique allele(s).

\begin{tabular}{cllccc}
\hline Samples & \multicolumn{1}{c}{1} & \multicolumn{1}{c}{2} & \multicolumn{1}{c}{3} & \multicolumn{1}{c}{4} & \multicolumn{1}{c}{5} \\
\hline 1 & 0 & 0.067 & 0.009 & 0.429 & 0.419 \\
2 & 0.253 & 0 & 0.067 & 0.383 & 0.460 \\
3 & 0.102 & 0.255 & 0 & 0.457 & 0.406 \\
4 & 0.573 & 0.551 & 0.592 & 1 & 0.433 \\
5 & 0.571 & 0.596 & 0.569 & 0.573 & 4 \\
\hline
\end{tabular}

\section{A}

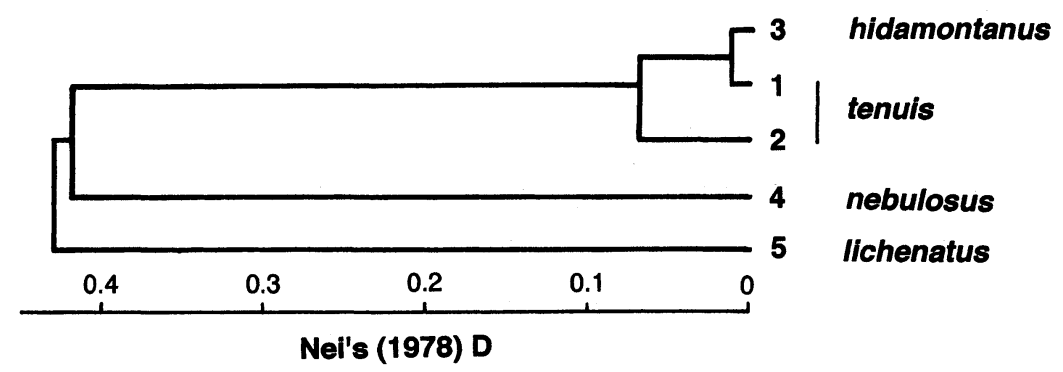

B

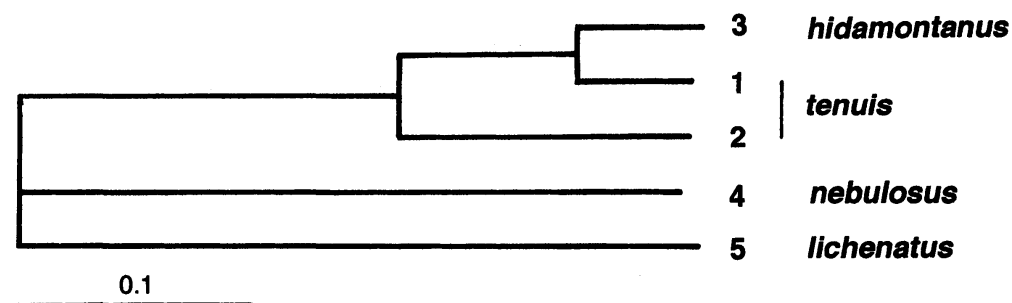

Modified Rogers' D (Wright, 1978)

FIG. 2. UPGMA tree based on Nei's (1978) unbiased genetic distances (A) and an NJ tree based on modified Rogers distances (Wright, 1978) rooted by the outgroup (sample 5) (B), among five samples studied. For sample numbers, refer to text. 


\section{DISCUSSION}

Recent biochemical reassessments of the Japanese small salamanders have resulted in elucidating the presence within a named species of many genetically distinct populations that require taxonomic splitting (cf. Matsui, 2000b). However, the present biochemical study of $H$. hidamontanus and $H$. tenuis has provided an opposite conclusion, i.e., the two species are genetically conspecific.

As shown by the values of $\mathrm{A}, \mathrm{P}$, and $\mathrm{H}$, each sample of $H$. hidamontanus and $H$. tenuis did not exhibit particularly great genetic differentiation within a locality, and so there was little possibility of there being a mixture of more than one species. The topotypic populations of $H$. tenuis from Toyama and $H$. hidamontanus from Nagano Prefectures first formed a group with the smallest genetic distance (Nei's $\mathrm{D}=0.01$ ) among all pairs compared, and the other population of $H$. tenuis from Gifu Prefecture had a sister relationship to this group. This very small genetic differentiation between the topotypic populations offers little support for taxonomic separation of these two species.

Matsui (1987) reported the Nei's (1978) D between $H$. hidamontanus and $H$. nebulosus to be 0.30 , which value is smaller than what we found in this study (0.46), notwithstanding the use of the same populations in the two studies. This discordance might have been induced by differences in specimens used, number of loci examined, and the electrophoretic conditions, especially the larger number of buffer systems employed in this study which might have separated more electromorphs. In this way, the absolute genetic distances derived from allozymic data themselves are variable, and were not directly used for outlining species boundaries. Relative distances from allozymic data, however, show a good taxonomic standard (Matsui, 2000b). Hynobius tenuis and $H$. hidamontanus are genetically not considered to be different species because their genetic distances are much smaller than are found among already named species or even within one species of Hynobius (D>0.22: e.g., Matsui 1987; Matsui et al. 2000; Nishikawa et al. 2001).

Allelic compositions of Gda-A, Gpi-A, and Ldh-A show some genetic fragmentation among $H$. tenuis and $H$. hidamontanus (samples 1-3). Matsui (1987) already reported genetic variations in $H$. hidamontanus. Namely, he found fixed differences in two loci and Nei's (1978) D of 0.20 between two populations of this species. However, he treated them as one species because of their morphological similarities.

Nambu (1991) argued that $H$. tenuis is specifically distinct from $H$. hidamontanus on the basis of different conditions in five skull characters (angle of articulation of maxilla and premaxilla, length and shape of maxilla, shape of premaxilla, shape of vomer, and proportion of vomerine teeth series). However, the skull morphology sometimes greatly varies even within a single species in Hynobius salamanders (Ebitani, 1952).

Our preliminary examinations of morphological variations in $H$. tenuis and $H$. hidamontanus specimens including those from their type localities revealed the absence of tangible differences in these two species (Matsui, 1996b; Matsui et al., unpublished data). In addition to these morphological similarities, descriptions in the literature (Matsui and Matsui, 1980; Nambu, 1983) and our extensive ecological observations in the field strongly indicate that they live and spawn in very similar habitats (slowly flowing water in marshes and swamps near montane forests), and share a similar ecological niche.

From these lines of evidence, we have no other choice but to conclude that $H$. tenuis Nambu, 1991, is a subjective junior synonym of $H$. hidamontanus Matsui, 1987, and that separation of the two species even at the subspecific level is not necessary. Although no further studies have been made, the population of a salamander from O-umi, Niigata Prefecture (Matsui, 1987) should also be included in this species from its diagnostic characteristics (see Matsui, 1987: 62). 
A case similar to that reported in the present paper has been known in some plethodontid salamanders; Feder et al. (1978) found little allozymic variation between Plethodon dunni and $P$. gordoni and also found that none of the diagnostic characters mentioned in the original description of $P$. gordoni were reliable. Consequently, they (Feder et al., 1978) synonymized $P$. gordoni as a color variant of $P$. dunni.

The discovery of $H$. hidamontanus (Matsui and Matsui, 1980; Matsui, 1987) and $H$. tenuis (Nambu, 1983, 1991) filled the distributional gaps of lentic breeding salamanders known previously (Sato, 1943; Nakamura and Uéno, 1963; Matsui and Miyazaki, 1984). The geohistory of the Japanese islands including the formation of the Fossa Magna (=ItoigawaShizuoka tectonic line) was supposed to have strongly affected the formation of patterns in distribution and divergence of these animals (Matsui, 1987; Matsui et al., 2000; Nishikawa et al., 2001).

Until now, the high montane region of the Hida Mountains could be considered a geographic barrier that had promoted the divergence of $H$. hidamontanus and $H$. tenuis, occurring on its eastern and western sides, respectively. The close genetic similarities demonstrated in the present study, however, indicate the invasion either (1) from west of the population ancestral to the present eastern population ( $H$. hidamontanus sensu stricto), or (2) from east of the ancestral population of the present western population $(H$. tenuis), possibly through a route north of the northernmost edge of the Hida Mountains.

The relationships among $H$. hidamontanus (sensu lato), $H$. nebulosus, and $H$. lichenatus were not clearly resolved in the present study, but through the use of more extensive samples, Matsui (1987) considered that $H$. hidamontanus belongs to one of the two large lineages of Japanese lentic breeding Hynobius and is phylogenetically closer to $H$. nebulosus from western Japan than to the eastern lineage including $H$. lichenatus. If this is the case, the first hypothesis advanced above seems more plausible. Hynobius hidamontanus (now including $H$. tenuis) occurs on the western side of the Fossa Magna and $H$. lichenatus occupies its eastern side (Matsui, 1987). If these two species actually belong to different lineages, as stated above, the possible dichotomy in the lentic breeding Hynobius in older times might have prevented further eastwards invasion of $H$. hidamontanus.

The present results greatly expand the range of distribution of $H$. hidamontanus, which was formerly limited to around the type locality in Hakuba Village, Nagano Prefecture (Matsui, 1987, 2000a). The species (sensu stricto) has been listed in Red Data Books for the reason that its habitats are limited and being destroyed (IUCN, 1996; Matsui, 2000a). We need to maintain this conservational status of $H$. hidamontanus because, even after synonymizing $H$. tenuis with it, the actual habitats, though ranging over a seemingly large area, are largely isolated from each other and the size of each local population is obviously very small (Matsui, 2001: 198).

\section{ACKNOWLEDGMENTS}

We would like to thank T. Abe and S. Tanabe for help in collecting the specimens examined. This work was supported by Grants-in-Aid to MM (No. 11640697) from the Ministry of Education, Science, Sports and Culture, Japan, through the Japan Society for the Promotion of Science and a grant from the Environment Agency of Japan (now the Ministry of Environment).

\section{LITERATURE CITED}

Ayala, F. J., J. R. Powell, M. L. Tracey, C. A. Mourão, and S. Pérez-SAlas. 1972. Enzyme variability in the Drosophila willistoni group. IV. Genetic variation in natural populations of Drosophila willistoni. Genetics 70(1): 113-139.

BOYER, S. H., D. C. FAINER, AND E. J. WATSON-WILliAMS. 1963. Lactate dehydro- 
genase variation from human blood: evidence for molecular subunit. Science 141(3581): 642-643.

Clayton, J. W. and D. N. Tretiak. 1972. Amine-citrate buffers for $\mathrm{pH}$ control in starch gel electrophoresis. J. Fish. Res. Board Canada 29(8): 1169-1172.

EBITANI, Y. 1952. On morphological relation between Hynobius nebulosus and $H$. tokyoensis. J. Sci. Hiroshima Univ. B-1 13(6): 173-184.

FEDER, J. H., G. Z. WURST, AND D. B. WAKE. 1978. Genetic variation in western salamanders of the genus Plethodon, and the status of Plethodon gordoni. Herpetologica 34(1): 64-69.

Felsenstein, J. 1993. PHYLIP (phylogeny inference package) Version 3.5c. Department of Genetics, Univ. Washington, Seattle.

Glaw, F., J. KOHLER, R. HOFRICHTER, AND A. DuBOIS. 1998. Systematik der Amphibien. Liste der rezenten Familien, Gattungen und Arten. p. 252-258. In: Hofrichter, R. (ed.), Amphibien. Naturbuch Verlag, Augsburg.

HighTON, R. 1999. Geographic protein variation and speciation in the salamanders of the Plethodon cinereus group with the description of two new species. Herpetologica 55(1): 43-90.

IUCN (International Union for Conservation of Nature and Natural Resources). 1996. 1996 IUCN Red List of Threatened Animals. IUCN, Gland, Switzerland and Cambridge, UK. 448 p.

JACKMAN, T. R. AND D. B. WAKE. 1994. Evolutionary and historical analysis of protein variation in the blotched forms of salamanders of the Ensatina complex (Amphibia: Plethodontidae). Evolution 48(3): 876-897.

MATSUI, M. 1987. Isozyme variation in salamanders of the nebulosus-lichenatus complex of the genus Hynobius from eastern Honshu, Japan, with a description of a new species. Jpn. J. Herpetol. 12(2): 50-64.

MATSUI, M. 1996a. Natural History of the Amphibia. Univ. Tokyo Press, Tokyo. 302 p. (in Japanese)

MATSUI, M. 1996b. Hynobius hidamontanus. p. 239-243. In: Japanese Society for the Protection of Fishery Resources (ed.), Basic Data on Rare Aquatic Wildlife of Japan (III). Tokyo. (in Japanese)

MATSUI, M. 2000a. Hynobius hidamontanus. p.
76-77. In: Environment Agency of Japan (ed.), The Red Data Book of Japan-Amphibians and Reptiles 2000. Japan Wildlife Research Center, Tokyo. (in Japanese with English summary)

MATSUI, M. 2000b. Batrachology of Japan and adjacent regions-a systematic review. Comp. Biochem. Physiol. B 126(2): 247-256.

MATsui, M. 2001. Order Caudata. p. 197-200. In: Japan Wildlife Research Center (ed.), The 5th National Survey on the Natural Environment-Reports of the Distributional Survey of Japanese Animals (Amphibians and Reptiles). Biodiversity Center of Japan (Nature Conservation Bureau, Ministry of the Environment, Japan), Fuji-Yoshida, Yamanashi. (in Japanese)

MATsui, M. AND M. MATSUI. 1980. Preliminary notes on a salamander of the Hynobius lichenatus complex found in Nagano Prefecture. Jpn. J. Herpetol. 8(4): 103-111. (in Japanese with English abstract)

MATSUI, M. AND K. MiYAZAKI. 1984. Hynobius takedai (Amphibia, Urodela), a new species of salamander from Japan. Zool. Sci. 1(4): 665671.

Matsui, M., H. Iwasawa, H. TaKahashi, T. HAYASHI, AND M. KUMAKURA. 1992. Invalid specific status of Hynobius sadoensis Sato: electrophoretic evidence (Amphibia: Caudata). J. Herpetol. 26(3): 308-315.

Matsui, M., Y. Misawa, K. NishiKawa, AND S. TANABE. 2000. Allozymic variation of Hynobius kimurae Dunn (Amphibia, Caudata). Comp. Biochem. Physiol. B 125(1): 115-125.

MAY, R. M. 1995. Conceptual aspects of the quantification of the extent of biological diversity. p. 13-20. In: Hawksworth, D. L. (ed.), Biodiversity-Measurement and estimation. Chapman and Hall, London.

NAKAMURA, K. AND S.-I. UÉNO. 1963. Japanese Reptiles and Amphibians in Colour. Hoikusha, Osaka. 214 p. (in Japanese)

NAMBU, H. 1983. A preliminary note on the salamander (Hynobius sp.) found in Ooyamamachi, Toyama Pref., and Oumi-machi, Niigata Pref., Central Japan. Bull. Toyama Sci. Mus. (5): $75-83+$ pl. 1. (in Japanese with English 
abstract)

NAMBU, H. 1991. Hynobius tenuis (Caudata, Hynobiidae), a new species of salamander from central Japan. Zool. Sci. 8(6): 991-997.

NEI, M. 1978. Estimation of average heterozygosity and genetic distance from a small number of individuals. Genetics 89(3): 583-590.

Nishikawa, K., M. Matsui, S. TANABe, AND S. SATO. 2001. Geographic enzyme variation in a Japanese salamander, Hynobius boulengeri Thompson (Amhibia: Caudata). Herpetologica 57(3): 281-294.

SAITOU, N. AND M. NEI. 1987. The neighborjoining method: a new method for reconstructing phylogenetic trees. Mol. Biol. Evol. 4(4): 406425.

SATO, I. 1943. A Monograph of the Tailed Batrachians of Japan. Nippon Shuppan-sya, Osaka. 520 p. (in Japanese)

SHAw, C. R. AND R. PRASAD. 1970. Starch gel electrophoresis of enzymes-a compilation of recipes. Biochem. Genet. 4(2): 297-330.

SNEATH, P. H. A. AND R. R. SOKAL. 1973. Numerical Taxonomy. W. H. Freeman, San Francisco. $573 \mathrm{p}$.

SWOFFORD, D. L. AND R. B. SElANDER. 1981. BIOSYS-1: a FORTRAN program for the comprehensive analysis of electrophoretic data in population genetics and systematics. J. Hered. 72(4): 281-283.
WrIGHT, S. 1978. Evolution and the Genetics of Populations, Vol. 4. Variability within and among Natural Populations. Univ. Chicago Press, Chicago.

\section{APPENDIX}

\section{Materials examined}

Voucher specimens used for electrophoresis are stored at the Graduate School of Human and Environmental Studies, Kyoto University (KUHE).

Sample 1: Hynobius tenuis from Ooyamamachi, Toyama Prefecture (KUHE 1323613248).

Sample 2: H. tenuis from Shirakawa-mura, Gifu Prefecture (KUHE 13262-13263, 1326513269).

Sample 3: $H$. hidamontanus from Hakubamura, Nagano Prefecture (KUHE 9481, 94849485, 9498-9510).

Sample 4: $H$. nebulosus from Hino-cho, Shiga Prefecture (KUHE 9599-9600, 1693716938).

Sample 5: $H$. lichenatus from Oguni-cho, Yamagata Prefecture (KUHE 18421, 1842618427, 18432, 18436-18437).

Accepted: 29 May 2002 